\title{
Soberania Alimentar no Machimbombo e na aldeia: gênero na perspectiva Sul-Sul
}

\author{
Rita Simone Liberato' (iD 0000-0002-3440-5562 \\ Laura Moutinho $^{2}$ (iD 0000-0001-6479-2711 \\ Isabel Noronha ${ }^{3}$ (D) 0000-0003-2666-9450 \\ Brigitte Bagnol ${ }^{4}$ (iD 0000-0002-0287-0152 \\ 'Universidade Federal de Sergipe, São Cristóvão, SE, Brasil. \\ 49100-000-ppged.ufs@gmail.com \\ 2Universidade de São Paulo, São Paulo, SP, Brasil. 05508-090 - ppgas@usp.br \\ 3Universidade de Coimbra, Centro de Estudos Sociais (CES), Coimbra, Portugal. \\ 3000-995-ces@ces.uc.pt \\ ${ }^{4}$ University of the Witwatersrand, Department of Anthropology, Johannesburg, \\ South Africa.
}

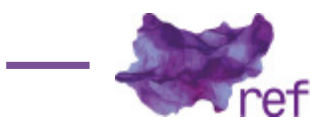

Resumo: Neste artigo são alinhavados olhares das mulheres do eixo Sul-Sul, suas aproximações e distanciamentos, a partir de categorias de análise que têm como marco a soberania e a Segurança Alimentar e Nutricional (SAN). Argumenta-se nessa reflexão acerca da importância da análise de gênero em perspectiva interseccional em dois cenários diversos. O primeiro cenário é a partir do ponto de vista das mukheristas, nome pelo qual são chamadas as mulheres moçambicanas que fazem o comércio entre Maputo (Moçambique) e Johannesburg (África do Sul). O segundo cenário é constituído pelas mulheres da aldeia Cinta Vermelha-Jundiba, que vivem na região do semiárido, no Vale do Jequitinhonha, no Brasil. Observar-se-á como, a partir de panos moçambicanos e sementes brasileiras, essas mulheres trançam suas sobrevivências.

Palavras-chave: Segurança alimentar e nutricional; relações de gênero; marcadores sociais da diferença; mukheristas/ Moçambique; aldeia Cinta Vermelha-Jundiba/Brasil

Food Sovereignty in Machimbombo and the Village: Gender in the South-South Perspective Abstract: In this article, we look at the South-South axis women, their approaches and distances, based on categories of analysis that have as a sovereignty and food and nutritional security. We defend the importance of an intersectional analysis both from the point of view of the Mukheristas, the way women who trade between Maputo, (Mozambique) and Johannesburg (South Africa) are called and from the perspective of women from the Cinta Vermelha-Jundiba village, living in the semiarid region of the Jequitinhonha Valley in Brazil. It will be observed how by trading clothesin the case of the Mozambican women andseeds for the Brazilians, these women braid their survival.

Keywords: Food security; Gender relations; Social markers of difference; Mukheristas/Mozambique; Cinta Vermelha-Jundiba/Brazil

\section{Introdução}

Historiadores/as que se debruçam sobre o comércio transatlântico de escravos africanos acentuam que é preciso um reconhecimento do peso que o passado exerce sobre o presente. Para eles/as, "tráfico, escravidão e abolição deixaram rastros de racismo e divisões sociais que permanecem sólidos no mundo atlântico de hoje" (Carlos LIBERATO; Mariana CANDIDO; Paul LOVEJOY, 2018, p. 2). 
Na modernidade, "significativamente, gênero e categorias raciais surgiram como dois eixos fundamentais ao longo dos quais as pessoas foram exploradas, e sociedades, estratificadas" (Oyèrónké OYİ WÙMí, 2004, p. 1). Mesmo sendo ressignificadas, as tragédias humanas vividas nos navios negreiros, de certo modo, perduram nos dias atuais. A fome é uma delas. Por compreender que essas tragédias são resultantes de um processo histórico e social, neste artigo exploramos a relação entre gênero e alimentos, questão quase que indissociável para os estudos da soberania e Segurança Alimentar e Nutricional (SAN). Argumentamos de modo mais amplo que um conjunto de marcadores sociais da diferença, em especial, gênero, "raça",' sexualidade e geração (Laura MOUTINHO, 2014) se constitui como central, em sua articulação com classe, para compreender a dinâmica sócio-histórica da relação entre gênero e alimentos. Como salientam Luiz Augusto FACCHINI et al. (2014) em análise de orientação quantitativa sobre o acesso, uso e qualidade de serviços de atenção à saúde de beneficiários/as e não beneficiados/as do programa do governo brasileiro, Bolsa Família, a renda tem um papel central para maior prevalência de insegurança alimentar em áreas das regiões Sul e Nordeste. Nas palavras dos autores:

Em ambas as regiões, maiores prevalências de insegurança alimentar moderada ou grave foram evidenciadas em domicílios nos quais a mulher era a chefe da família, a cor da pele materna era preta ou parda, havia maior número de moradores com até sete anos, entre 7 e 17 anos e no máximo um entre 18 e 59, o chefe da família trabalhava sem carteira assinada ou não estava trabalhando/nunca havia trabalhado, a escolaridade materna e a renda per capita eram menores e recebiam o Bolsa Família (FACCHINI et al., 2014, p. 166).

Os autores e autoras notam que esses mesmos domicílios, especialmente, os do Nordeste, possuíam renda média per capita duas vezes menor que os demais domicílios, chamando atenção ao final para a importância de se aumentar os valores e os benefícios por parte do governo como forma de diminuir a insegurança alimentar.

Nosso ponto de partida são os materiais vinculados à pesquisa de campo, realizada via cartografia audiovisual na África do Sul e Moçambique, em 2017, ${ }^{2}$ durante o trabalho etnográfico viabilizado pelo projeto PROÁFRICA/CNPq "A Vizinhança nas entrelinhas". ${ }^{3}$

Entrecruzamos o material etnográfico dessa viagem com alguns resultantes da pesquisa doutoral de Rita Simone LIBERATO (2018), recém-concluída, sobre a aldeia Cinta Vermelha-Jundiba, uma comunidade indígena do semiárido de Minas Gerais. Nela, mulheres de dois grupos étnicos distintos, Pankararu e Pataxó, lutam para (re)construir seus modos de vida, assentando-os nos saberes de suas ancestrais (tias, avós e parentes) e nos princípios da permacultura e agroecologia. Sobretudo, tecem práticas de resiliência para que as gerações futuras alcancem o Bem Viver. Reflexão realizada apoiando-se na forma como Fredrik BARTH (1998) trabalhou com a ideia de fronteiras: os grupos não são isolados, mas resultantes de processos de negociações e contradições, forjados nas entradas e saídas que realizam em espaços e grupos distintos.

Nesse contexto, são alinhavados os olhares das mulheres do eixo Sul-Sul, suas aproximações e distanciamentos, a partir de duas categorias de análise. A primeira refere-se à soberania alimentar, compreendida a partir do Fórum Mundial sobre Soberania alimentar (2001) como

o direito de os povos definirem suas próprias políticas e estratégias sustentáveis de produção, distribuição e consumo de alimentos que garantam o direito à alimentação para toda a população, com base na pequena e média produção, respeitando suas próprias culturas e a diversidade dos modos camponeses, pesqueiros e indígenas de produção agropecuária, de comercialização e gestão dos espaços rurais, nos quais a mulher desempenha um papel fundamental [...]. A soberania alimentar é a via para erradicar a fome e a desnutrição e garantir a segurança alimentar duradoura e sustentável para os povos (Renato MALUF; Márcio REIS, 2013, p. 20).

A segunda diz respeito à SAN, que consiste

na realização do direito de todos ao acesso regular e permanente a alimentos de qualidade, em quantidade suficiente, sem comprometer o acesso a outras necessidades essenciais, tendo como base práticas alimentares promotoras da saúde, que respeitem a diversidade cultural e que sejam social, econômica e ambientalmente sustentáveis (CONSEA, 2004).

\footnotetext{
'Usamos a categoria "raça" entre aspas para marcar sua importância na vida social na delimitação das oportunidades de vida e de acesso dos indivíduos a bens, status e a formação educacional. Apesar de inúmeros esforços de promissoras tecnologias sociais que visavam à sua erradicação, como na África do Sul pós-apartheid, essa forma de classificar e hierarquizar os sujeitos se mantém ativa no cotidiano dos contextos estudados - ainda que informadas por diferentes usos e valores.

2 Participaram do trade de 2017 realizado entre Johannesburg, África do Sul e Maputo, Moçambique, Laura Moutinho, Rita Simone Liberato, Paulo Neves e Brigitte Bagnol.

${ }^{3}$ Essa reflexẫo foi viabilizada a partir da pesquisa e experiência mais ampla das autoras no projeto "A Vizinhança nas entrelinhas: alianças e conflitos, trocas (des)iguais e cooperação entre Moçambique e África do Sul" (projeto selecionado na Chamada MCTI/CNPq n 46/2014 - Programa de Cooperação em Ciência, Tecnologia e Inovação com Países da África-PROÁFRICA), financiado pelo CNPq e coordenado por Laura Moutinho. Além de uma ampla rede de colaborações, integraram a pesquisa: Brigitte Bagnol, Esmeralda Mariano, José Ricardo Ayres, Lilia Schwarcz, Paulo Sérgio da Costa Neves, Pedro Lopes e Rita Simone Liberato, tendo sido incorporadas ao longo do processo as pesquisadoras Denise Dias Barros, Carla Braga, Solange Rocha, Gabriela Calazans, Isabel Noronha e Susan Holland-Muter.
} 
Assegurar a alimentação adequada, portanto, é assegurar o direito à vida. Para garantir esse direito humano, deve-se reconhecer que o silêncio da "fome oculta" (Josué de CASTRO, 1946) é uma das principais faces da insegurança alimentar, manifestada através de três fatores: classe social ou nível de renda, condição de gênero e geracional e origens étnicas e "raciais". Logo, desde essa perspectiva, a diversidade nutricional e cultural das pessoas deve ser considerada (MALUF; REIS, 2013).

Contudo, deve-se frisar que a relação entre gênero e alimentos já tem sido explorada em muitos estudos. Há um consenso emergente, bem como um crescente volume de evidências de que é necessário abordar a desigualdade de gênero para contribuir para aliviar a fome, a pobreza e o desemprego (Brigitte BAGNOL; Robyn ALDERS; Robyn McCONCHIE, 2015; David GUEST; BAGNOL, 2018). A partir das análises das brasileiras Emma SILIPRANDI (2013), Telma Castello BRANCO (2013), Cecília ROCHA et al. (2013), somadas às da moçambicana Esmeralda Mariano (Denise PIMENTA; MOUTINHO, 2017), e da francesa Brigitte Bagnol e seus colegas (BAGNOL; ALDERS; McCONCHIE, 2015) é crível supor que há uma convergência entre os sinais de pobreza social e riqueza econômica que, nos dois países, desaguam na questão de gênero, observadas, como dito, numa perspectiva interseccional.

As pesquisadoras do Brasil assinalam que a compreensão da relação quase que indissociável entre SAN e gênero é fulcral para a formulação das políticas públicas. Já a investigadora de Moçambique, Esmeralda Mariano, argumenta que a violência nos discursos do poder político se multiplica em novas formas silenciadas de violência (PIMENTA; MOUTINHO, 2017), uma característica marcante da insegurança alimentar (ausência de SAN). Nesse bojo, as mulheres tanto da zona urbana quanto rural são expostas diariamente a desafios de sobrevivência.

Em termos mundiais, as mulheres constituem metade da população e são um terço de toda força de trabalho. Contudo, estima-se que ganham apenas um décimo da renda global, e possuem $1 \%$ da propriedade. Ainda que esses dados sejam da segunda Conferência Mundial sobre a Mulher, realizada em 1980, a situação não mudou muito (SILIPRANDI, 2013).

No contexto de um mundo altamente globalizado, os papéis das mulheres indígenas, por exemplo, foram corroídos pela perda de recursos naturais e esgotamento dos ecossistemas. Sob sistemas de opressão e violência, elas compartilham experiências exitosas, ainda que muitas vezes não sejam reconhecidas (Chandra ROY, 2004).

Em 2015, a população rural na América Latina e Caribe correspondia aproximadamente a $21 \%$ da população total, cerca de 129 milhões de pessoas. Agricultoras, coletoras, pescadoras, trabalhadoras assalariadas e artesãs forjam $20 \%$ da força de trabalho agrícola, somente na América Latina, de acordo com dados da FAO (2018).

Elas enfrentam sobrecarga de trabalho devido à divisão sexual das tarefas, pois acumulam também o cuidado dos filhos, idosos e doentes. Seu trabalho é invisibilizado e possuem baixo acesso a terra, água, sementes e insumos. Enfrentam dificuldades para participação política, têm pouca autonomia econômica e nos processos decisórios. Nos grupos indígenas verificam-se entre as mulheres taxas mais altas de pobreza e desnutrição do que em qualquer outro grupo social. Elas chegam a ganhar até quatro vezes menos do que os homens (Miriam NOBRE; Carla HORA, 2017).

Esse quadro revela as desigualdades de gênero, compreendidas como

um elemento constitutivo das relações sociais, baseado nas diferenças percebidas entre os sexos. É uma forma primária de dar significado às relações de poder [...], pois fornece um meio de se decodificar e compreender as complexas conexões entre várias formas de interações entre mulheres e homens (Joan SCOTT, 1995, p. 86-89).

Se as questões de gênero, somadas às de "raça", etnia, sexualidade e classe social, aumentam a vulnerabilidade, por consequência, as mulheres indígenas sofrem discriminação tripla, por seu gênero, origem e pobreza (Monica GRAYLEY, 2018). Elas carregam uma soma de significativos estigmas para o pleno gozo dos seus direitos e são obrigadas a desenvolver habilidades e estratégias para sobreviverem. Enfrentam, de forma geral, a violência de gênero, incluído o abuso sexual (ROY, 2004).

Nobre e Hora (2017) argumentam que, apesar dos desafios históricos, observa-se em toda região da América Latina e Caribe o "crescente protagonismo das mulheres em defesa dos territórios, [...] pois buscam soluções para o Bem Viver coletivo. Elas são as principais responsáveis pela transmissão do conhecimento, manejo agroecológico e uso das plantas medicinais" (p. 2). No entanto, somente nessa região com 45 milhões de indígenas, 15\% sofrem de insegurança alimentar e extrema pobreza (FAO, 2018).

No recente fórum Empoderar a las Mujeres Indígenas para erradicar el hambre y la malnutrición en América Latina y el Caribe, realizado pela FAO e Secretaria de Agricultura, Genaderia, Desarollo Rural, Pesca e Alimentación (SAGARPA), nos dias 12 e 13 de janeiro de 2018, na cidade do México, representantes de 14 países da América Latina e Caribe chegaram ao consenso de que as mulheres são cruciais para a proteção da biodiversidade, adaptação às mudanças climáticas e diversificação das dietas (UNRIC, 2015). 
No Brasil, mulheres extrativistas como as Quebradeiras de Coco Babaçu do Maranhão, Catadoras de Mangaba de Sergipe, Coletoras de Umbu do sertão da Bahia, dentre tantas outras, estão se organizando e denunciando a precariedade das suas condições materiais para sobreviver, bem como as violações que sofrem. Como as demais mulheres da zona rural, elas são, de forma geral, responsáveis pela produção de alimentos através de hortas, criação de pequenos animais, preparo das refeições e, ainda, são as principais mentoras das questões que envolvem a saúde e educação das crianças e idosos (SILIPRANDI, 2013).

Suas vidas estão diretamente atreladas aos recursos naturais. Com o avanço dos projetos de monocultura e mineração nas suas regiões, bem como os impactos provocados pelas mudanças climáticas, passam por situações de risco, assim como as moçambicanas diante das empresas de exploração dos recursos minerais. Siliprandi (2013) ressalta que, considerando-se a importância dos recursos produtivos na determinação da situação de pobreza e insegurança alimentar, se deduz que as mulheres e as crianças são as mais afetadas pela fome e desnutrição. "Excluídas dos espaços de poder, suas questões têm pouco apelo e visibilidade política" (SILIPRANDI, 2013, p. 195). Mesmo tendo conhecimento em áreas relevantes para a promoção dos direitos, como a SAN, "seu conhecimento e sua importância como sujeitos políticos são pouco valorizados e reconhecidos" (SILIPRANDI, 2013, p. 189).

Diante desse quadro, observa-se que há grupos de mulheres que estão operando de forma silenciosa e sistemática para sua sobrevivência, cruzando as fronteiras da África do Sul e Moçambique. O mesmo movimento ocorre em alguns territórios do semiárido do Vale do Jequitinhonha, no Brasil.

De modo geral, elas fazem entradas e saídas em espaços urbanos para comercializar artesanato confeccionado por suas próprias mãos, utilizando como matéria-prima sementes que plantam, coletam, tingem e costuram, como é o caso das mulheres da aldeia Cinta VermelhaJundiba, no Brasil. Ou, como no caso das moçambicanas, adquirem produtos em Maputo para comercializar na África do Sul, cruzando a fronteira de Ressano Garcia.

Nesse movimento, servem-se das capulanas, tecidos de $1,80 \mathrm{~cm} \times 1,00$, comuns em diversos países africanos, feitos de algodão e provenientes da Índia, China e Tanzânia. As capulanas são utilizadas para envolver o corpo da cintura até os pés das mulheres, mas também para amarrar bebês nas costas, cobrir a cabeça, carregar objetos e protegê-las das intempéries (Helena ASSUNÇÃO; Aiúba Ali AIÚBA, 2017). Esses panos são objeto de desejo em todo o mundo. $O$ documentário de Camilo de SOUSA e Isabel NORONHA (2014) intitulado "Na dobra da capulana" mostra os múltiplos sentidos e usos de um pano que é constitutivo da ideia e da própria experiência de ser mulher em Moçambique.

Retomaremos esse assunto mais à frente. Por agora, nas páginas que se seguem, iremos discorrer sobre as práticas da aldeia Cinta Vermelha-Jundiba na elaboração das biojoias e o impacto da comercialização dessas peças na SAN da comunidade indígena brasileira. Do mesmo modo, iremos tratar do comércio das capulanas e outros produtos, realizado pelas mulheres conhecidas, em Moçambique, como Mukheristas.

Por uma questão metodológica, este artigo está dividido em duas partes, além desta introdução e da conclusão. Foi realizado a partir da análise das narrativas (Paul RICOEUR, 1994) gravadas em vídeo e áudio com as atrizes sociais citadas, mas também de investigação bibliográfica para levantamento das referências teóricas já construídas sobre o objeto em tela, a fim de ampliá-las.

\section{Mulheres Indígenas do semiárido brasileiro e soberania alimentar}

A aldeia Cinta Vermelha-Jundiba foi criada em 2005, em Araçuaí, norte de Minas Gerais, região do semiárido. Surgiu a partir do desejo de um grupo de cinco famílias Pankararu e Pataxó, originárias de Pernambuco e Sul da Bahia, respectivamente, de construir um projeto de vida assentado na permacultura e agroecologia. Ao decidir comprar os 68 hectares de terra, as lideranças fundaram uma associação e tomaram um empréstimo bancário, num programa de crédito fundiário. Garantiram que iriam pagá-lo com a produção de artesanato.

Duas questões merecem atenção neste ponto da análise. A primeira diz respeito ao fato de que este é o primeiro caso, no Brasil, em que grupos étnicos distintos decidem não esperar na fila de demarcação de terras da Fundação Nacional do Índio (FUNAl), e comprar terra numa região de semiárido. A segunda refere-se ao fato de que assumiram pagar o empréstimo com a renda oriunda do artesanato.

Diante dos dados, não seria exagero afirmar que as mulheres estavam costurando o pano de fundo da negociação, ainda que os homens tenham assumido os trâmites legais do processo, uma vez que elas são as artesãs da comunidade. Semeadoras, coletoras, tingidoras e cerzidoras dos colares, pulseiras, brincos e demais biojoias da aldeia, elas acumulam, muitas vezes e de diferentes formas, conforme relataram, jornadas triplas de trabalho. Além de cuidarem da alimentação, da casa, das crianças, dos mais velhos etc., ainda estudam, confeccionam o 
artesanato, elaboram projetos para captação de recursos, realizam projetos, ao mesmo tempo que circulam por uma vasta rede de sociabilidades.

A capacidade do grupo em imaginar, articular e realizar propostas deu à aldeia o Prêmio Culturas Indígenas, concedido pelo Ministério da Educação e Cultura e Serviço Social do Comércio de São Paulo, em 2009. O trabalho que recebeu essa importante chancela foi referente ao cultivo de plantas medicinais, condimentos e leguminosas, o Okhá-Kahab [Casa da Cura, Saúde e Harmonia], coordenado por uma mulher: Cleonice Pankararu.

Como se sabe, a região do semiárido apresenta uma série de desafios para os pequenos agricultores familiares. A escassez de chuvas e, no caso da aldeia em tela, o solo degradado por projetos de pecuária desde o período colonial, requisitou um manejo complexo, com tecnologias apreendidas também através das múltiplas entradas e saídas das indígenas na sociedade nacional.

Nesse ir e vir da própria corporeidade e das sensibilidades, as pautas relativas à saúde e educação estiveram no centro das reivindicações das Pankararu e Pataxó da aldeia. As agendas sociais das mulheres incluem a luta pelo acesso à água potável, mas também recursos para a produção de alimentos sem a utilização de agrotóxicos e adubos químicos. Por essa via, defendem a utilização de técnicas de agricultura centradas na agroecologia, uma prática que envolve inovação tecnológica resultante dos saberes do povo e do acadêmico (Victor TOLEDO, 2016) e a permacultura, técnica de cultivo baseada em práticas tradicionais, que visa ao cuidado de todas as formas de vida (Bill MOLLISON, 1990). Cultivam plantas medicinais, catalogam receitas e técnicas que consideram importantes para a prevenção e cura de doenças.

Como não poderia deixar de ser, as mulheres também defendem que uma educação adequada, cuja metodologia promova a formação de seus filhos para serem "cidadãos de bem e livres de aprisionamentos" (Cleonice PANKARARU, 2014), é vital para a sobrevivência da comunidade em direção ao Bem Viver. Assentado no termo Sumak Kawsay, língua Quechua, Suma Qamaã em Aymara ou Buen Vivir/Vivir Bien, na tradução mais recorrente, o Bem Viver é uma perspectiva em construção, que se realiza nas práticas que brotam "desde de dentro". Ou seja, ações que considerem as estratégias de convivência com a natureza, através da conjugação das condições ecológicas de um território com o manejo cultural do espaço (Enrique LEFF, 2016; Alberto ACOSTA, 2015; David CHOQUEHUANCA, 2010; Marcos ARRUDA, 2003).

As mulheres indígenas da aldeia em tela acreditam que essa perspectiva pode contribuir para conectar os direitos dos seres humanos aos direitos da natureza. Por esse viés, "valorizam o ser ao invés do ter" (YTXAHÁ PANKARARU-PATAXÓ, entrevista gravada em 2015 por Rita Simone Liberato).

Seguindo essas noções, as mulheres, com a ajuda de suas famílias, conforme relatam, reflorestaram áreas, criaram um herbário para cultivar plantas medicinais, condimentos e leguminosas. Nesse processo, estrategicamente, árvores e arbustos que assegurariam uma alimentação que consideram saudável, as práticas de benzimento e rituais, além de sementes necessárias para a produção do artesanato, uma das principais fontes de renda da comunidade, foram plantadas. Valeram-se dessa estratégia porque suas histórias familiares, afirmam, foram marcadas por escassez, guerras e pelo enfrentamento de necessidades vitais básicas, como água potável e alimento adequado.

Na mobilidade estratégica, neste trânsito que realizam para circular em diferentes espaços oficiais, também articularam, através de sua rede de alianças com indígenas e não indígenas, suas inserções políticas nos Conselhos, Fóruns e Movimentos Sociais da região e do estado. Pesquisadoras dos saberes tradicionais, elas têm acessado os espaços universitários e concluído cursos de graduação em Licenciatura Intercultural Indígena e Ciências Biológicas na Universidade Federal de Minas Gerais (UFMG). Duas jovens são graduadas em Gestão Ambiental no Instituto Federal do Norte de Minas Gerais, e uma liderança está concluindo a graduação em Pedagogia na UFMG. Apesar disso tudo, ainda assim, as relações de gênero são marcadas pela divisão sexual do trabalho.

De modo geral, a discussão do conceito de gênero entre os grupos étnicos é algo recente. Segundo Jurema MACHADO (2012), "o importante papel desempenhado pelas mulheres no cotidiano das aldeias e na luta dos povos nunca foi negligenciado, mas sim, em alguns momentos, forçadamente invisível" (p. 30).

Pesquisadores (Rafael KARIRI; Suzanne COSTA, 2014; MACHADO, 2012; Gérsem LUCIANO, 2013; Hosana SANTOS, 2009) posicionam Etelvina Santana da Silva (Bruno Pacheco de OLIVEIRA, 2015) como atriz social crucial na discussão do papel da mulher nas aldeias indígenas brasileiras. Indicada para o Prêmio Nobel da Paz em 2005 por seu trabalho de luta pelos direitos dos povos indígenas, seu percurso assinala, a partir de sua própria experiência como mulher indígena migrante da zona rural para um grande centro urbano, a situação de vulnerabilidade à SAN e à própria vida.

O depoimento de Maninha, gravado em vídeo no LACED/MN/UFRJ (s/d), é emoldurado por uma angústia gerada diante dos desafios enfrentados na cidade, que acentuaram uma crise de 
identidade e, ao mesmo tempo, pela sua busca ao acesso à educação formal como estratégia para solucionar os problemas também da demarcação das terras de sua comunidade.

Ainda que ela não tenha conseguido permanecer no Recife, após concluir o Ensino Médio, por falta de bolsa de estudo, conforme sublinha sua narrativa, sua luta abriu clivagens importantes para que as relações de gênero da Articulação dos Povos e Organizações Indígenas do Nordeste (APOINME), Minas Gerais e Espírito Santo entrassem na agenda do movimento social indígena.

A APOINME incentivou as mulheres a saírem do isolamento das aldeias. Houve certa quebra dessa posição. Respondendo os convites de Maninha, algumas indígenas, que no futuro formariam a aldeia Cinta Vermelha-Jundiba, passaram a participar, inclusive, dos centros de decisão e de poder. Como afirma Cleonice Pankararu: "Maninha circulava em vários espaços como liderança política das mulheres indígenas. A conheci na década de 1990 e foi muito importante para minha formação" (Entrevista gravada por Rita Simone Liberato com a autora em dezembro de 2017).

Filha da cacica Benvinda Pankararu, Cleonice desenvolve atividades como bióloga e agroecologista, ao mesmo tempo que acumula inúmeras tarefas de cuidado com a casa, filhas, neta, saúde da comunidade, trabalho de pesquisa no curso de especialização em Sociobiodiversidade e Sustentabilidade do Cerrado/UnB, e trabalho de articulação política junto a seu irmão, cacique To'ê.

Esse sobrevoo sobre sua agenda abre chaves importantes para este ponto do estudo, porque reflete, de modo geral, o perfil das mulheres da comunidade que estão em movimento para lutar contra uma posição, dadas as devidas proporções, que lhes foi destinada historicamente. Muito influenciada por Dona Benvina, que "sempre foi guerreira, pois é conhecida pela sua posição firme em defesa dos direitos indígenas, e defesa das mulheres" (Diário de Campo, 24/12/ 17), Cleonice possui um perfil híbrido.

Ainda que ela escape aos papéis construídos socialmente, tanto no âmbito das tarefas domésticas quanto das subalternidades relativas às demandas políticas, a bióloga Pankararu se sobrecarrega para conciliar a educação de filhas, neta e sobrinhos, promover a saúde do grupo e agenciar pautas de luta. Da mesma forma, Géo Pataxó, casada com o cacique, dispensa uma grande parte do seu tempo à produção das biojoias (colares, pulseiras, brincos e bolsas), cultivo da pequena roça, horta, cuidado com a casa, trabalho como merendeira da escola e estudante do curso de Pedagogia da UFMG.

As duas indígenas ainda comercializam artesanato na cidade e nos espaços que acessam através da sua rede de sociabilidades. Saem do território com suas biojoias e retornam com alimentos, livros e calçados para suas famílias. Declaram sentir prazer com essa atividade. A jovem Uakyrê, Pankararu-Pataxó, afirma que o artesanato "é feito a partir da nossa espiritualidade. Fazemos colares porque gostamos. Também é uma importante fonte de renda para a comunidade" (Entrevista gravada pela autora em 2015).

Logo, tanto as mulheres mais velhas quanto as mais jovens cerzem formas de sobrevivência a partir da comercialização de seus produtos, atravessando fronteiras e negociando modos próprios de entrar e sair da sociedade nacional. Nesse movimento, sofrem influências de grupos externos, ao mesmo tempo que os influenciam. No trabalho de pesquisa de campo realizado no PROÁFRICACNPq "A vizinhança nas entrelinhas", percebe-se um cruzamento desse modo de vida das indígenas do semiárido de Minas Gerais com o das mulheres conhecidas como Mukheristas, na fronteira da África do Sul e Moçambique. É deste assunto que o próximo tópico trata.

\section{Mukheristas, capulanas e os desafios da sobrevivência}

Nossa primeira jornada coletiva com as mulheres moçambicanas teve início na Park Station de Johannesburg, em 2017. A rodoviária movimentada, com sua arquitetura moderna e letreiros digitais, é um espaço de contrastes, também marcado pela venda de fastfood de redes internacionais e dos assustados negociantes que, no chão, organizam suas frutas e legumes, cuidadosamente embalados.

Nossa espera pelo machimbombo (ônibus) durou quase cinco horas. O embarque previsto para as $8 \mathrm{~h}$ somente aconteceu às $12 \mathrm{~h} 30$. O atraso abriu espaço para que iniciássemos um diálogo com cerca de dez mulheres que vivem da comercialização de produtos entre Moçambique e África do Sul. Suas atividades compõem um dos eixos do nosso estudo e parte desse cenário pode ser visto no ensaio produzido por Moutinho e Liberato (2018).

Seus trajes, cabelos bem trançados, adereços, as grandes caixas e bolsas que carregavam refletiam, de certo modo, tanto suas origens quanto o trabalho que envolve suas viagens. Algumas, segundo relataram, hospedavam-se na residência de familiares. Outras ficavam em pequenas pensões ao redor da rodoviária. Jovens, maduras e idosas, naquele mês de fevereiro em que estávamos pesquisando, formavam um grupo de mulheres que experimenta desafios comuns, conforme nos revelaram durante o percurso dentro do machimbombo e, depois, em Maputo.

Logo, nossas entrevistas foram iniciadas ainda na fila da espera e seguiram estrada adentro. Ao todo, foram quase 15 horas de interlocução. O atraso de quase cinco horas da partida, os 550 
km entre Maputo e Johannesburg, bem como a espera para verificação dos documentos na tensa fronteira entre um país e outro, foram utilizados para discutir temas em torno das relações de gênero, saúde, alimentação, capulanas, entre outros.

Generosas, as mulheres transformaram o ônibus, por volta das 16h, quando já estávamos muito próximas umas das outras e da fronteira, num espaço de troca de saberes, experiências, dores e reivindicações. Entre uma narrativa e outra, cantos foram entoados e lágrimas enxugadas nas capulanas. Em certo instante, esses panos passaram a ser retirados de bolsas por todos os lados. O mosaico de cores do algodão formou uma espécie de manto comum. Cerziu gritos de luta. Em coro, diziam: "moçambicana que é moçambicana, usa capulana".

O silêncio inicial foi cedendo espaço para muitos risos, perguntas sobre o Brasil. Conversávamos em português, mas em determinados momentos, elas o misturavam ao inglês, numa espécie de hibridação de linguagens própria das pessoas que vivem cruzando fronteiras. Uma das líderes do grupo, dona Maria de Lourdes, 56 anos, informou que viajava duas vezes por mês. Seu trabalho iniciava-se em Maputo, a partir do levantamento das necessidades de suas clientes. Eletrodomésticos, artigos de decoração, doces, roupas e tantos outros bens eram encomendados. Ela os comprava na África do Sul e, no seu retorno à capital de Moçambique, seguia entregando-os às suas clientes. Muitas delas, pelo que percebemos, eram pequenas comerciantes no Mercado do Peixe.

A partir de certo momento, as narrativas de sofrimento e luta pela sobrevivência começaram a ser enunciadas roucamente: "No tempo da guerra, eu trazia açúcar, sabão, muitas outras coisas, pois em Moçambique não havia nem mesmo esses produtos. Perdi muitas amigas durante a guerra na década de 1980. Foi muito triste", relatou, ao mencionar a guerra civil que assolou o país por 16 anos, após a independência de Portugal, em 1975. Dona Maria informou que não saía para Johannesburg com as malas vazias. Levava capulanas para revender, dada a grande procura. "As capulanas de Maputo são as mais bonitas. Como eu sei escolher, as pessoas querem comprar comigo", ressaltou sem esconder certo orgulho.

Muito preocupada com sua saúde, pois sofre de diabetes, informou que um dos desafios de suas viagens era o acesso a alimentos adequados. Faz tratamento tanto na África do Sul quanto em Maputo, utilizando, como não é pouco comum, serviços de saúde dos dois países. Em Johannesburg soubemos de mulheres que traziam de Harare, no Zimbábue, pílulas anticoncepcionais para as suas conterrâneas. Mesmo tendo acesso a contraceptivos fornecidos pelo Estado, as zimbabuanas preferiam pagar pelo produto ao qual estavam acostumadas. Daí a importância de se entender, como sustentamos no projeto PROÁFRICA/CNPq, "A vizinhança nas entrelinhas", a África Austral como uma região interconectada e marcada pela mobilidade. Fazse, pois, necessário incorporar "olhares cruzados" sobre as perspectivas coloniais que informam a região (MOUTINHO; Wilson TRAJANO FILHO; Andrea LOBO, 2017). Dona Maria também faz uso de chás para atenuar o diabetes. Mãe de um único filho, que vivia na Cidade do Cabo, na África do Sul, disse que seus encontros com ele eram difíceis, dadas as condições financeiras.

Dona Maria de Lourdes foi casada com um militar. Com expressão de tristeza, relatou que era enganada por seu ex-marido, quando se ausentava para seu trabalho de mukherista, entre os dois países. "Ele pegava meu dinheiro. Gastava com outras mulheres. Quando descobri, não quis mais. Depois ele pediu para voltar, quando estava doente. Cuidei dele, mas pouco depois faleceu" (Entrevista gravada pela equipe do Projeto PROÁFRICA/CNPq, em fevereiro de 2017).

Uma outra viajante, Maria das Graças, 44 anos, relatou um caso de poligamia familiar. Seu avô possuía cinco mulheres. "Eu não gosto de poligamia", frisou, afirmando que nas décadas de 1950 e 1960, seu pai foi trabalhar na pecuária junto a missionários religiosos. "Por isso, ele estudou e construiu outra vida, pois era assimilado", declarou em tom de distinção. Vale lembrar que a política de assimilação levada a cabo por França e Portugal visava dar substracto à ideia de aculturação dos povos colonizados, afastando-os da sua cultura, e formando uma eleite privilegiada que tinha como referência cultural a sociedade urbana colonial portuguesa (José Luís CABAÇO, 2009). ${ }^{4}$

Essa afirmação de Maria das Graças causou certo burburinho entre as demais mulheres. Percebemos que, de certa forma, quando ela destacou a condição de seu grupo familiar estar

\footnotetext{
${ }^{4}$ Com a ascensão do Estado Novo em Portugal, foi publicado um conjunto de dispositivos legais que culmina com o Ato Colonial (1930), que vigorou até 1961, definindo um quadro jurídico-institucional geral de uma nova política para os territórios sob dominação portuguesa e traçando as linhas gerais de toda a organização interna das colónias, o direito consuetudinário e estabelecendo um novo quadro de relação administrativa com as culturas locais que passaria a dividir os povos africanos entre indígenas e assimilados. Escapando pela aculturação - categoria geral de indígenas -, à qual não eram reconhecidos quaisquer direitos, os assimilados e seus descendentes deixavam de estar obrigados ao trabalho forçado nas plantações e obras públicas, podiam frequentar a escola e ter acesso à saúde pública, adquirir propriedade, o que significava a possibilidade de uma relativa mobilidade na escala social colonial. A aquisição do estatuto de assimilado era feita mediante um exame em que o candidato tinha de apresentar formação escolar, domínio da língua portuguesa falada e escrita, comprovar a posse de bens e um quotidiano familiar marcado por uma "vida cristã" e ter abandonado por completo os "usos e costumes da raça negra" em favor de hábitos culturais europeus, nos quais a alimentação era um factor determinante.
} 
ligado a uma categoria que refletia o que considerava uma certa "ascensão social", as demais se posicionaram com visível desconforto. Ela sublinhou a sua condição de certo "privilégio", e o seu casamento com um trabalhador da mineração. "Temos casa em Maputo para as férias, mas há 25 anos vivemos na África do Sul, em Johannesburg. Meus quatro filhos hoje estão estudando e trabalhando". Sua viagem estava sendo marcada pela busca de documentos para um de seus filhos ter acesso a uma bolsa que Ihe possibilitaria a entrada em uma universidade na África do Sul (ver sobre o tema Paulo NEVES et al., 2019, nesta Seção Temática).

Mas, à semelhança das outras mulheres, foi a guerra civil que inicialmente empurrou a família de Maria das Graças para a cidade: "Houve guerra, e nessa época, 1986, saímos de Massinga ${ }^{5}$ e viemos morar em Maputo", destacou. A nível demográfico, o crescimento rápido e descontrolado dos bairros periféricos de Maputo (representando cinco dos sete distritos municipais desta cidade), foi acompanhado por uma grande degradação das condições de vida para os seus habitantes. A cobertura dos serviços de base (água, escolas, postos de saúde etc.) continuou a ser muito baixa. Apesar dos investimentos verdadeiros nas áreas de turismo, infraestruturas rodoviárias, comunicações, indústria, a taxa de desemprego continua sendo elevada, em particular dos jovens ( $40 \%$ dos que estão procurando um emprego têm menos de 20 anos de idade) e as mulheres (60\% das mulheres estão à procura do seu primeiro emprego). É necessário assinalar também que, em 2002, a taxa ponderada de prevalência do HIV/AIDS em Moçambique já era de $13,6 \%$ de acordo com o Plano Nacional de Combate ao HIV/SIDA de 2004. Em Beira, atingia 26\% (CNCS, 2004), o que teve também um grande impacto na desestruturação do tecido familiar, com a morte ou adoecimento de uma grande parte da população adulta ativa (Manuel ARAÚJO, 2005).

A narrativa de Maria das Graças em torno da experiência da guerra acentua a situação de risco familiar e violência permanente à qual foi exposta. "Foi horrível. Muitos massacres. Não gosto de lembrar. Um dia fui visitar minha mãe em Massinga e vi uma cena muito difícil. Mataram a população, cortaram o pescoço e colocaram as cabeças em varas na estrada [...] Não foi fácil". "Quando nos mudamos era tempo do apartheid, e não foi fácil". Sublinhando a continuidade de uma história de violência que perpassa já várias décadas e que acompanha a luta pela sobrevivência destas mulheres, ela acrescenta:

Não estamos sossegados. Moçambique está em paz. Mas, na África do Sul, ainda matam os que vêm de outros países. Semana passada mataram os pequenos vendedores somalianos em Pretória, e levaram as mercadorias deles. Em 2008, fiquei muito chateada e decidi voltar para minha terra, Moçambique. Aqui nós temos gás, diamante, ouro. Aqui nós vamos enriquecer. Na África do Sul acabou tudo e eles abusam das pessoas de fora. Em 2015 começaram essa mania de ameaçar os estrangeiros. Eles não deixam esse apartheid.

A narrativa de Maria das Graças expressa, entre outros aspectos, como o manto do passado histórico recente de apartheid ainda hoje se reflete nas relações dos sul-africanos para com os imigrantes africanos na África do Sul. Uma realidade complexa que retém e ressignifica formas de exclusão racial e de gênero (MOUTINHO; Pedro LOPES; Marcio ZAMBONI; Mario RIBAS; Elaine SALO, 2010; BAGNOL; Zethu MATEBENI; Anne SIMON; Thomas BLASER; Sandra MANUEL; MOUTINHO, 2010) e igualmente espacial e LGBT (MATEBENI, 2017). A moçambicana descreveu crueldades visíveis nas estacas do seu caminho, que marcam uma guerra no presente. Contudo, uma forma de violência não tão visível marca o percurso das mukheristas. Segundo Miriam Nobre et al. (2017), dos 815 milhões de famintos do planeta, 489 milhões são de países afetados por conflitos.

A fome, desnutrição, sobrepeso e obesidade são sintomas da falta de acesso a uma alimentação adequada, que forneça alimentos saudáveis em quantidade suficiente e extremamente necessários para uma vida digna e ativa. O consumo de produtos industrializados e uma dieta rica em proteínas e gorduras afetam hoje em Moçambique a saúde de inúmeras mulheres, cujo estilo de vida se alterou fortemente por efeito das mudanças profundas, que foram acontecendo ao longo de mais de quatro décadas, desde a independência do país. Tempo disponível, custo dos produtos e espaço para cultivo são alguns dos fatores referidos pelas mulheres entrevistadas como originários da mudança da cultura alimentar da maioria das famílias da cidade de Maputo. Todavia, esses fatores apontam a necessidade de uma compreensão mais ampla do contexto de vida, tremendamente complexo, marcado por mudanças históricas, políticas, econômicas, sociais e institucionais rápidas e violentas no passado recente, e dos seus efeitos num presente onde tais mudanças se diluem como história e memória, mas são visíveis nas estratégias de sobrevivência desenhadas para tentar escapar à precariedade da vida que foram determinadas para a maioria dos habitantes desta cidade. Maria das Graças aponta o êxodo do campo para a cidade em razão da guerra como sendo a origem destas mudanças:

A alimentação mudou muito. A chuva dava bem, colhíamos muitos alimentos na Machamba [roça]. Com o andar do tempo, com a guerra, não havia tempo de fazer nada. Ninguém

${ }_{5}^{5}$ Distrito do Sul de Moçambique, situado a cerca de 540 km de Maputo. 
conseguia ficar no campo e cultivar. Todo mundo corria para as cidades, onde já faltava comida. Era uma calamidade. Pedíamos socorro aos outros países. Dependíamos de cartão de abastecimento.

No discurso dessa mukherista, Maria das Graças, é possível encontrar elementos que nos dão pistas de como o mínimo vital (Antonio CANDIDO, 2003) foi afetado pelas mudanças políticas e econômicas na estrutura social do país, tanto no campo como nas cidades. A opção por uma política socialista, concomitante ao regime de apartheid da África do Sul e da Rodésia do Sul (atual Zimbábue), levaria à eclosão de uma guerra que rapidamente tomaria os contornos de uma guerra civil que durou 16 anos, vitimando mais de um milhão de moçambicanos e fazendo deslocar mais de três milhões. A cidade de Maputo foi uma das que mais famílias deslocadas recebeu, particularmente mulheres e crianças, que procuravam refúgio junto aos seus familiares já aí residentes, ocupando praticamente todos os espaços disponíveis e alterando a composição sexual dos agregados familiares. Mantendo os seus hábitos rurais, essas famílias procuraram sempre continuar a prática da agricultura de subsistência em qualquer pequeno terreno encontrado, mas os terrenos foram ficando escassos e o espaço disponível para tal foi sendo reduzido (Manuel ARAÚJO, 2005). No contexto de uma economia incipiente, as medidas tomadas pelo primeiro governo independente para fazer face a esta situação foram de controle do espaço urbano e suburbano e racionamento alimentar:

Durante a guerra, os bairros foram divididos em quarteirões. Eram 45 casas que eram controladas por um chefe. Numa casa ele sabia quantas pessoas viviam. Numa casa de cinco pessoas, as famílias recebiam por adulto $2 \mathrm{~kg}$ de arroz, meio quilo de feijão e amendoim. As crianças até 15 anos, meio kg por mês. Tínhamos que saber como cozinhar essa comida para passarmos o mês. Tínhamos um cartão de abastecimento que nos dava acesso ao que eles nos davam. Já nem falávamos de frango. Marcávamos a bicha [fila] de madrugada, com nossos cestos, para receber os alimentos. Eram longas, longas, bichas. Quando estava calor, não era fácil. Às vezes fechava a cantina e nós não conseguíamos o que comer... é aí que as coisas já começaram a se estragar, aí a população já não se alimentava bem porque dependia da cantina...

Esse contexto é geralmente visto como resultado do somatório de mudanças na política do governo após a independência: "as três grandes reestruturações econômicas experimentadas em Moçambique, nas últimas cinco décadas, foram incapazes de estabelecer ligações e fluxos saudáveis e sustentáveis entre o crescimento econômico e o desenvolvimento humano. [...] Tais fracassos

parecem estar diretamente ligados ao facto de as forças político-económicas que os influenciaram serem prisioneiras de ideais de modernidade e de quadros institucionais que não privilegiam o alargamento efectivo de escolhas e oportunidades da maioria da população moçambicana, num contexto de desenvolvimento integrado na diversidade sociocultural do país (António FRANCISCO, 2010).

Para Maria das Graças e diversas mulheres da sua geração em transição do meio rural para o urbano, esse contexto de precariedade e dependência marcou uma drástica mudança da cultura alimentar. Hoje, para ela, comida boa é batata frita, pão, queijo, salada de pepino, alface, o que denota a influência dos alimentos da África do Sul em sua dieta. Em contraste, informou que sua mãe gosta de comer banana, carapau, peixe, folha de abóbora com coco, amendoim e camarão seco. Essa narrativa ativou na sua memória uma relação afetiva com os sabores. Ela passou a elencar comidas que gostava. "Podemos cozinhar arroz com couve, que vai bem com coco e camarão. Folha de mandioca, batata doce, mandioca. Gostamos muito também de caranguejo", afirmava sorrindo. Tradicionalmente, a cultura alimentar do Sul de Moçambique baseia-se na produção de milho, mandioca e batata doce e feijão, geralmente cultivadas em regime de agricultura de subsistência, em pequenas machambas familiares situadas em torno da casa, em terrenos familiares ou comunitários perto dela ou junto ao rio mais próximo. Mas, ao contrário de muitas outras regiões, onde só os tubérculos ou os grãos destas plantas são utilizados para a confecção de alimentos, no Sul de Moçambique as folhas de algumas destas plantas, ricas em vitaminas e minerais (a que genericamente se chama "verduras"), vêm sendo desde tempos imemoriais usadas na alimentação diária. Pensada à luz dos padrões nutricionais recentes, esta dieta poderia ser considerada das mais ricas, equilibradas e saudáveis. Contudo, as transformações econômicas e sociais que se registraram em Moçambique, desde a época da colonização portuguesa à atualidade e na relação de Moçambique com o contexto regional mais amplo, foram afastando gradualmente as populações da sua cultura alimentar de origem.

Tomás SITOE (2009), em artigo publicado no site do Slow Food, descreve a comida tradicional moçambicana como sendo composta por um número diversificado de receitas preparadas com alimentos cultivados nas roças. "Matapa, cacana, xiquinha, xinguinhonguana, macoufo, nhangana, entre outros possuem uma característica comum: o fato de que o amendoim pilado é 
condimento principal do caril, o qual é sempre servido acompanhado da farinha de milho". Maria Eunice MACIEL e Renata MENASCHE (2003) afirmam que o processo de construção de uma cozinha num país colonizado é geralmente resultante de um conjunto de influências, que geram processo complexo que implica confrontos, associações e exclusões, uma vez que ela é não apenas resultado, mas indicador dos valores que tanto incorpora como exibe. Nesse sentido, Sitoe (2009) considera que foi marcante na cozinha moçambicana a influência da cultura portuguesa, que impôs uma mudança nos hábitos alimentares africanos como parte do "processo civilizatório" dos "indígenas" procurando lhes incutir novos valores em relação à alimentação, como por exemplo o consumo de arroz ao invés de farinha de milho e a introdução de pratos feitos à base de óleos vegetais (frituras) em vez do amendoim e coco e proteínas animais (carne, peixe, bacalhau, galinha, mariscos etc.) em vez das tradicionais "verduras" (SITOE, 2009). Este autor cita como exemplo desta imposição o fato de que o tipo de alimentação usado na casa dos candidatos a "assimilados" (categoria social que atestava que alguém tinha assimilado o suficiente da cultura do colonizador para ser admitido na sociedade, adquirindo o direito de ter uma caderneta de assimilado (não um bilhete de identidade) que permitia inscrever os filhos na escola, ser atendido no posto de saúde, poder concorrer a determinados cargos de baixo escalão na função pública) seria um dos marcadores que atestava o grau de "civilização" da população. Procedia-se uma espécie de exame, sendo enviado um examinador que observava se a família se sentava à mesa, como manuseava os talheres e se a comida servida era cozinhada segundo os padrões da culinária portuguesa.

Os pais das crianças que iam à escola no tempo colonial "deveriam atestar, entre outras coisas, a capacidade de assegurar para seus filhos uma merenda diária, composta por um sanduíche contendo bife, manteiga, queijo e outros alimentos modernos [grifo do autor]" (SITOE, 2009). A valorização deste tipo de alimento é também resultante da dieta nas minas da África do Sul, para onde grande parte da mão de obra masculina do Sul de Moçambique emigrava por longos períodos, visitando intermitentemente a terra natal para casar ou visitar a família, trazendo consigo presentes modernos, entre eles alimentos. E teve continuidade num cenário em que o racionamento alimentar determinado pela guerra e um contexto de economia socialista raramente incluíam este tipo de itens, que só eram adquiridos nos países vizinhos.

A migração do campo para a cidade afetou também os hábitos de amamentação dos recém-nascidos. Maria das Graças afirma que hoje as mulheres no campo ainda o fazem. "Mas na cidade, as mães seguem para trabalhar fora de casa e deixam as crianças com as babás", frisou. De acordo com a UNICEF (2013), apenas $43 \%$ das crianças com menos de seis meses recebem aleitamento materno exclusivo. "Tanto a porcentagem de amamentação contínua nas crianças entre 20 e 23 meses (52\%) como a duração mediana do aleitamento materno (21 meses) mostraram um declínio nos últimos anos" (UNICEF, 2013).

Esse cenário apresenta contraste com o Brasil, país referência no quesito aleitamento materno. Para a ONUBR (2016), a regulamentação da Lei de Amamentação, assinada em novembro de 2015, que limita a comercialização de substitutos do leite materno, promove a licença maternidade de 4 a 6 meses cruciais para esse destaque mundial, pois as mulheres brasileiras são responsáveis por " $89,2 \%$ da coleta dos 1,1 milhão de litros de leite doados e beneficiaram $79,1 \%$ de todos os recémnascidos atendidos nesses espaços. O país possui o maior número de doadoras de leite do mundo".

\section{Alinhavando cruzamentos}

De modo geral, há um conjunto de conexões entre as mulheres entrevistadas em Moçambique e as Pankararu e Pataxó da aldeia Cinta Vermelha-Jundiba. Elas assumem jornadas triplas de trabalho, comercializam produtos para fortalecer a renda familiar e, portanto, a soberania e a SAN. Foram expostas a guerras e conflitos, possuem histórias familiares ligadas à escassez de alimentos e vivem de entradas e saídas em diversos grupos sociais.

No quesito educação, lutam para que seus filhos acessem as universidades, pois compreendem que uma educação adequada poderá lhes proporcionar uma posição mais digna e livre, conforme relatam. Nos dois países, elas utilizam adereços tradicionais em suas viagens, como marcadores da sua identidade nos espaços em que circulam. No caso das brasileiras, elas elaboram seus colares e pulseiras com sementes que plantaram. No das moçambicanas, elas os adquirem em lojas especializadas. A capulana, pano de algodão colorido quase universalmente usado em todo Moçambique, serve de base para a confecção de lenços, bolsas, saias etc., que distinguem as mulheres moçambicanas das demais.

Os dois grupos de mulheres procuram alimentar-se da forma que consideram mais adequada para si, o que significa dizer que os alimentos tradicionais, principalmente à base de mandioca, têm papel fundamental neste processo. Procuram fazer uso do chá, mas utilizam também as prescrições oriundas dos serviços públicos de saúde disponíveis. Isso implica dizer que mesclam modos de cura apreendidos com suas avós e tias com os desenvolvidos a partir de estudos científicos. 
De todo o modo, ainda que o peso das atividades que realizam exija um trabalho árduo de preparação, de certa forma ele desagua num de tipo de liberdade dos afazeres domésticos. Ao mesmo tempo que estão no trânsito necessário para comercializar seus produtos, as mulheres entrevistadas demonstram relativa autonomia nas suas formas de caminhar e se relacionar. Acessam saberes de uma rede que, em sua maioria, também é composta por mulheres oriundas de seus grupos familiares, de afeto ou de instituições. Nessa troca, da forma como se pode interpretar a partir de seus relatos, elas fortalecem não somente a renda familiar, mas a si mesmas.

Logo, dobrando os panos africanos ou cerzindo sementes para construir colares, essas mulheres do Sul seguem trançando sobrevivência por diferentes caminhos. Nesse percurso há muito ainda a ser estudado, uma vez que pistas relativas às formas de comunicação utilizadas nesse processo, assédios sofridos nos espaços urbanos e a formação da geração mais jovem nos dão pistas de paradoxos, tensões e construções que possibilitam importantes pontos de partida para estudos futuros na perspectiva Sul-Sul. O texto de Carla Braga (2019) explora essas possibilidades na interface com a saúde. Trata-se de uma perspectiva que, como visto, não se resume ao viés econômico e precisa ser observada a partir da perspectiva interseccional de gênero para a compreensão dos determinantes acerca da soberania e segurança alimentar, bem como do acesso a bens e à saúde.

\section{Referências}

ACOSTA, Alberto. O bem viver: uma oportunidade para imaginar outros mundos. Tradução de Tadeu Breda. São Paulo: Autonomia Literária; Elefante, 2015.

ARAÚJO, Manuel. "Cidade de Maputo. Espaços contrastantes: do urbano ao rural". X ENCONTRO DE GEÓGRAFOS DA AMÉRICA LATINA. 20 a 26 de março de 2005, Anais, Universidade de São Paulo, São Paulo.

ARRUDA, Marcos. Humanizar o infra-humano: a formação do ser humano integral: homo evolutivo, práxis e economia solidária. Petrópolis: Vozes, 2003.

ASSUNÇÃO, Helena; ALI AlÚBA, Aiúba. "Capulanas e macuti-camadas de tecidos, folhas e histórias". Cadernos de Campo, Araraquara, n. 23, p. 101-124, jul./dez. 2017.

BAGNOL, Brigitte; MATEBENI, Zethu; SIMON, Anne; BLASER, Thomas; MANUEL, Sandra; MOUTINHO, Laura. "Transforming Youth Identities: Interactions across 'Races/ Colours/ Ethnicities', Gender, Classes and Sexualities in Johannesburg, South Africa". Sexuality Research and Social Policy, n. 7, p. 283-297, 2010. Disponível em http://www.springerlink.com. DOI: 10.1007/s13178-010-0027-9.

BAGNOL, Brigitte; ALDERS, Robyn; McCONCHIE, Robyn. "Gender issues in human, animal and plant health using an ecohealth perspective". Environment and Natural Resources Research, n. 1, p. 6276, 2015.

BARTH, Fredrik. "Grupos étnicos e suas fronteiras". In: POUTIGNAT, Philippe; STREIFF-FENART, Jocelyne. Teorias da etnicidade. São Paulo: EDUNESP, 1998. p. 185-227.

BRAGA, Carla Teofilo. “'Machamba não é trabalho!': HIV/SIDA e Produção Agrícola no centro de Moçambique". Revista Estudos Feministas, Florianópolis, v. 27, n. 3, e671 75, 2019.

BRANCO, Telma Castello. "Gênero e políticas públicas no Brasil”. In: ROCHA, Cecília; BURLANDY, Luciene; MAGALHÃES, Rosana (Orgs.). Segurança alimentar e nutricional: perspectivas, aprendizados e desafios para as políticas públicas. Rio de Janeiro: Fiocruz, 2013. p. 171-185.

CABAÇO, José Luís. Moçambique: identidade, colonialismo e libertação. São Paulo: EDUNESP, 2009.

CANDIDO, Antonio. Os parceiros do Rio Bonito: estudo sobre o caipira paulista e a transformação dos seus meios de vida. 10. ed. São Paulo: Editora 34, 2003.

CASTRO, Josué de. Geografia da fome. Rio de Janeiro: O Cruzeiro, 1946.

CHOQUEHUANCA, David. 25 Postulados para entender el vivir bien (manuscrito sin fecha), 2010. Disponível em https://indigenaslibertarios.blogcindario.com/2010/02/00055-25-postulados-paraentender-el-vivir-bien-entrevista-con-david-choquehuanca-bolivia.html. Acesso em 31/07/2019.

CNCS. CONSELHO Nacional de Combate ao HIV/SIDA. 2004. Plano National de Combate ao HIV/ SIDA. Maputo: Conselho Nacional de Combate ao HIV/SIDA, 2004. 
CONSEA. Princípios e diretrizes de uma política de Segurança Alimentar e Nutricional: textos e referências da II Conferência Nacional de Segurança Alimentar e Nutricional. Brasília: Positiva, 2004. Disponível em http://www.ipea.gov.br/participacao/images/pdfs/conferencias/Seguranca_ Alimentar_II/textos_referencia_2_conferencia_seguranca_alimentar.pdf.

GUEST, David; BAGNOL, Brigitte. "Gender, health and smallholder farming". In: WALTON, Merrilyn (Ed.). One Planet, One Health. Sydney: Sydney University Press, 2018.

FACCHINI, Luiz Augusto et al. "Insegurança alimentar no Nordeste e Sul do Brasil: magnitude, fatores associados e padrões de renda per capita para redução das iniqüidades". Cadernos de Saúde Pública, v. 30, p. 161-174, 2014. (ENSP. Impresso)

FAO. "The female face of farming". Infographics, 2018. Disponível em http://www.fao.org/gender/ resources/infographics/the-female-face-of-farming/en/.

FRANCISCO, António. "Moçambique: protecção social no contexto de um estado falido mas não falhado". In: BRITO, Luís de; CASTELO-BRANCO, Carlos Nuno; CHICHAVA, Sérgio; FRANCISCO, António (Eds.). Protecção Social: Abordagens, Desafios e Experiências para Moçambique. Maputo: IESE, 2010. p. 37-95.

GRAYLEY, Monica. "Chefe da FAO diz que mulheres indígenas sofrem 'discriminação tripla'”, ONU News, Nova lorque, 15/01/201 8. Disponível em https://news.un.org/pt/story/2018/01/1609271.

KARIRI, Rafael; COSTA, Suzane. "Conversações sobre povos indígenas em práxis autobiográficas". Pontos de Interrogação, v. 4, n. 2, p. 85-98, 2014.

LEFF, Enrique. Aposta pela vida: imaginação sociológica e imaginários sociais nos territórios ambientais do Sul. Rio de Janeiro: Vozes, 2016.

LIBERATO, Carlos; CANDIDO, Mariana; LOVEJOY, Paul; SOULODRE-LA-FRANCE, Renée (Orgs.). Laços Atlânticos: África e africanos durante a era do comércio transatlântico de escravos. Luanda: Ministério da Cultura; Museu Nacional da Escravatura, 2018.

LIBERATO, Rita Simone. Comunicação, saberes e sabores: estratégias de sobrevivência e práticas de bem viver na aldeia Cinta Vermelha-Jundiba. 2018. 333f. Tese (Doutorado em Educação) Programa de Pós-Graduação em Educação, Universidade Federal de Sergipe, 2018.

LUCIANO, Gérsem José dos Santos. Educação para manejo do mundo: entre a escola ideal e a escola real no Alto Rio Negro. Rio de Janeiro: Contracapa; LACED, 2013.

MACHADO, Jurema. "Gênero e mulheres indígenas no Nordeste". In: LEAL, Caroline; ENEIDA, Heloisa; ANDRADE, Lara (Orgs.). Guerreiras: a força da mulher indígena. Recife: CCLF, 2012. p. 30-31.

MACIEL, Maria Eunice; MENASCHE, Renata. "Alimentação e cultura, identidade e cidadania. Você tem fome de quê?". Democracia Viva, Rio de Janeiro, n. 16, p. 3-7, 2003.

MALUF, Renato; REIS, Márcio. "Conceitos e princípios de segurança alimentar e nutricional". In: ROCHA, Cecília; BURLANDY, Luciene; MAGALHÃES, Rosana (Orgs.). Segurança alimentar e nutricional: perspectivas, aprendizados e desafios para as políticas públicas. Rio de Janeiro: Fiocruz, 2013. p. $15-42$.

MANINHA XUCURU-KARIRI. Direção do vídeo: Bruno Pacheco de Oliveira. Coordenação do Projeto Educação Superior de Indígena no Brasil: Antonio Carlos de Souza Lima. Rio de Janeiro: LACED/MN/ UFRJ; CNPq; FAPERJ-Ford Foundation, 8 min 38 s, 2015. Disponível em https://www.youtube.com/ watch?v=32yYmfDmti8. Acesso em 30/01/2018.

MATEBENI, Zethu. "Perspectivas do Sul sobre relações de gênero e sexualidades: uma intervenção queer". Revista de Antropologia, São Paulo, v. 60, n. 3, p. 26-44, dez. 2017. DOI: $10.11606 / 2179-$ 0892.ra.2017.141826.

MOLLISON, Bill. Permaculture: a practical guide for a sustainable future. Washington: Island Press, 1990.

MOUTINHO, Laura; LIBERATO, Rita Simone. "Cenas de delicadeza: o trade entre Johannesburg, África do Sul e Maputo, Moçambique". Amazônica: Revista de Antropologia, v. 10, p. 824-838, 2018. 
MOUTINHO, Laura; TRAJANO FILHO, Wilson; LOBO, Andrea. "Algumas reflexões". Revista de Antropologia, v. 60, n. 3, p. 7-25, 2017. DOI: 10.11606/2179-0892.ra.2017.141823.

MOUTINHO, Laura. "Diferenças e desigualdades negociadas: raça, sexualidade e gênero em produções acadêmicas recentes". Cadernos Pagu, UNICAMP, p. 201-248, 2014.

MOUTINHO, Laura; LOPES, Pedro; ZAMBONI, Marcio; RIBAS, Mario; SALO, Elaine. "Retóricas ambivalentes: ressentimentos e negociações em contextos de sociabilidade juvenil na Cidade do Cabo (África do Sul)". Cadernos Pagu, UNICAMP, v. 35, p. 139-176, 2010. (Impresso)

NAS dobras da capulana. Realização e Produção: Camilo de Sousa e Isabel Noronha. Moçambique, Documentário, 2014, 30 min.

NEVES, Paulo Sérgio da Costa; MOUTINHO, Laura; SCHWARCZ, Lilia Katri Moritz. "Herança colonial confrontada: reflexões sobre África do Sul, Brasil e Estados Unidos". Revista Estudos Feministas, Florianópolis, v. 27, n. 3, e66960, 2019.

NOBRE, Miriam et al. Atlas de las mujeres rurales de América Latina y El Caribe: al tiempo de la vida e los hechos. Santiago de Chile: FAO, 2017. Disponível em http://www.fao.org/3/a-i7916s.pdf.

ONU. Relatório da missão ao Brasil da relatora especial sobre os direitos dos povos indígenas, 08/ 08/2016. Disponível em http://unsr.vłaulicorpuz.org/site/images/docs/country/2016-brazil-a-hrc-3342-add-1-portugues.pdf. Acesso em 31/01/2018.

ONUBR. Política de aleitamento materno do Brasil é referência mundial, diz OMS, 05/03/2016. Disponível em https://nacoesunidas.org/politica-de-aleitamento-materno-do-brasil-e-referenciamundial-diz-oms/. Acesso em 10/06/2018.

OYÌ WÙMí, Oyèrónké. Conceituando o gênero: os fundamentos eurocêntricos dos conceitos feministas e o desafio das epistemologias africanas. Tradução para uso didático de OYİ WùMí, Oyèrónké. "Conceptualizing Gender: The Eurocentric Foundations of Feminist Concepts and the challenge of African Epistemologies. African Gender Scholarship: Concepts, Methodologies and Paradigms". CODESRIA Gender Series, Dakar, CODESRIA, v. 1, p. 1-8, 2004.

PANKARARU, Cleonice. Os desafios do professor-educador na (re)construção de novos caminhos para o ensino fundamental e médio: educação, formação e transformação. 2014. 44f. Trabalho de Conclusão de Curso (Licenciatura em Ciências Biológicas) - Universidade Federal de Minas Gerais, Araçuaí, 2014.

PIMENTA, Denise; MOUTINHO, Laura. "Um encontro com Esmeralda Mariano: reflexões sobre o fazer antropológico em Moçambique e alhures". Cadernos de Campo, Araraquara, n. 23, p. 13-24, jul./ dez 2017.

RICOEUR, Paul. Tempo e narrativa. Campinas: Papirus, 1994.

ROCHA, Cecília; BURLANDY, Luciene; MAGALHÃES, Rosana (Orgs.). Segurança alimentar e nutricional: perspectivas, aprendizados e desafios para as políticas públicas. Rio de Janeiro: Fiocruz, 2013.

ROY, Chandra K. "Indigenous women: a gender perspective". Journal of Aboriginal Policy Research Consortium International, n. 1, p. 3-38, 2004. Disponível em https://ir.lib.uwo.ca/cgi/ viewcontent.cgi? article =1250\&context=aprci. Acesso em 10/01/2018.

SANTOS, Hosana Celi Oliveira e. Dinâmicas sociais e estratégias territoriais: a organização social Xukuru no processo de retomada. 2009. 160f. Dissertação (Mestrado em Antropologia) - Programa de Pós-Graduação em Antropologia, Universidade Federal de Pernambuco, Recife, 2009.

SCOTT, Joan. "Gênero: uma categoria útil para análise histórica". Educação e Realidade, v. 20, n. 2, p. 71-79, jul./dez. 1995.

SILIPRANDI, Emma. "A alimentação como um tema político das mulheres". In: ROCHA, Cecília; BURLANDY, Luciene; MAGALHÃES, Rosana (Orgs.). Segurança Alimentar e Nutricional: perspectivas, aprendizados e desafios para as políticas públicas. Rio de Janeiro: Fiocruz, 2013. p. 187-198.

SITOE, Tomás. Colonização e independência em Moçambique: hábitos alimentares em mudança, 14/09/2009. Disponível em https://www.slowfoodbrasil.com/textos/alimentacao-e-cultura/307colonizacao-e-independencia-em-mocambique-habitos-alimentares-em-mudanca. Acesso em 05/06/2019. 
TOLEDO, Victor. "A agroecologia é uma revolução epistemológica - Diana Quiroz entrevista Victor Toledo". Agriculturas, v. 13, n. 1, p. 42-45, 2016.

UNICEF Mozambique. O aleitamento materno é a intervenção mais eficaz e barata na história para salvar vidas de crianças, 01/08/2013. Disponível em http://www.unicef.org.mz/o-aleitamentomaterno-e-a-intervencao-mais-eficaz-e-barata-na-historia-para-salvar-vidas-de-criancas/. Acesso em 08/06/2018.

UNRIC. Objetivos de desenvolvimento sustentável: 17 objetivos para transformar o mundo, 2015. Disponível em https://www.unric.org/pt/17-objetivos-de-desenvolvimento-sustentavel.

Rita Simone Liberato (rsimone@se.sesc.com.br) é doutora em Educação pela Universidade Federal de Sergipe (UFS). Realizou Doutorado Sanduíche na Ryerson University, Canadá, com bolsa da CAPES. Mestre em Comunicação e Cultura pela Ryerson University and York University (2009). Diplomada em Canadian Journalism for Internationally Trained Writers no Sheridan College - Graduate Programs (2008). Coordenadora do Programa Cultura do SESC Sergipe. Produtora, editora e diretora de vídeos participativos.

Laura Moutinho (Imoutinho@usp.br) é Professora Associada (Livre-Docente) do Departamento de Antropologia e do Programa de Pós-Graduação em Antropologia (PPGAS), ambos da USP, e doutora em Antropologia Cultural pela UFRJ. Realizou Pós-Doutorado na Universidade de Princeton, é bolsista produtividade nível $1 \mathrm{D}$ do CNPq, editora da Revista de Antropologia e coordenadora da Comissão Projeto Editorial da Associação Brasileira de Antropologia (ABA).

Isabel Noronha (isabelhnoronha@gmail.com) é licenciada em Psicologia Clínica e Aconselhamento pelo Instituto Superior Politécnico Universitário (ISPU), onde também lecionou. É mestre em Saúde Mental e Clínica Social pela Universidade de Léon, na Espanha, e doutora em Antropologia pela Unicamp. Foi membro-fundador da primeira cooperativa independente de Vídeo ("Coopimagem") e da Associação Moçambicana de Cineastas.

Brigitte Bagnol (bagnbolbrigitte@gmail.com) tem mais de 35 anos de experiência na região da África Austral (vivendo em Moçambique e na África do Sul) como antropóloga especializada em desenvolvimento, antropologia da ecologia, comunicação, sexualidade, antropologia da saúde, "Uma Saúde e nutrição com lentes de gênero". Ela é uma consultora independente que trabalha na África e na Ásia para diferentes agências nacionais e internacionais para dar treinamento, desenhar ou avaliar projetos e conduzir pesquisas.

\section{COMO CITAR ESSE ARTIGO DE ACORDO COM AS NORMAS DA REVISTA}

LIBERATO, Rita Simone; MOUTINHO, Laura; NORONHA, Isabel; BAGNOL, Brigitte. "Soberania Alimentar no Machimbombo e na aldeia: gênero na perspectiva Sul-Sul". Revista Estudos Feministas, Florianópolis, v. 27, n. 3, e66961, 2019.

\section{CONTRIBUIÇÃO DE AUTORIA}

Rita Simone Liberato: concebeu a estrutura do artigo, montando o primeiro draft, participou da coleta e análise de dados, bem como da elaboração do manuscrito, redação, discriminação e discussão de resultados.

Laura Moutinho: coleta e análise de dados, elaboração do manuscrito, redação, discriminação e discussão de resultados.

Isabel Noronha: coleta e análise de dados, elaboração do manuscrito, redação, discriminação e discussão de resultados.

Brigitte Bagnol: coleta e análise de dados, elaboração do manuscrito, redação, discriminação e discussão de resultados.

A coleta de dados foi feita por todas em diferentes momentos e a análise, elaboração do manuscrito, redação e discriminação de resultados foi discutida e trabalhada por todas. 


\section{FINANCIAMENTO}

O CNPq foi o principal órgão financiador através do Edital PROÁFRICA e da bolsa produtividade em pesquisa de uma das autoras; CAPES (através de bolsa sanduíche de uma das participantes do projeto PROÁFRICA); FAPESP: Processo 16/09840-0 (através de bolsas de estudos para pósgraduandos que participaram do projeto PROÁFRICA, bem como pelo financiamento do Simpósio "Olhares cruzados para a África: trânsitos e mediações", realizado na USP e na 30 RBA/UFPB, 2016) e FAPITEC-SE por meio da concessão de bolsa de doutorado. A pesquisa contou ainda com o apoio do Programa de Pós-Graduação em Antropologia da USP.

\section{CONSENTIMENTO DE USO DE IMAGEM}

Não se aplica.

APROVAÇÃO DE COMITÊ DE ÉTICA EM PESQUISA

Não se aplica.

\section{CONFLITO DE INTERESSES}

Não se aplica.

\section{LICENÇA DE USO}

Este artigo está licenciado sob a Licença Creative Commons CC-BY International. Com essa licença você pode compartilhar, adaptar, criar para qualquer fim, desde que atribua a autoria da obra.

\section{HISTÓRICO}

Recebido em 07/08/2019

Aprovado em 16/08/2019 